\title{
STUDY OF MAMMOGRAPHY REPORTS MADE BETWEEN 2015 AND 2019
}

Marina Hernandes Carvalho1, Pedro César Garcia Gonçalves', Gabriel Carvalho Carnelossi², Maria Júlia Carvalho Carnelossi², Felipe Colombelli Pacca ${ }^{1}$

${ }^{1}$ Faculdade de Medicida em São José do Rio Preto - São José do Rio Preto (SP), Brazil

¿União das Faculdades dos Grandes Lagos - São José do Rio Preto (SP), Brazil.

Introduction: Screening and early diagnosis are crucial strategies for the detection of breast cancer. In Brazil, the Ministry of Health recommends annual clinical screening in women over 40 years of age, with the addition of biennial mammography for those aged between 50 and 69 years. However, high-risk patients should have mammography annually after the age of 35 years. Objectives: To study the reasons for mammography screening in the age group 50 to 69 years. Method: This is an ecological study of the number of patients per mammography report according to age group, from 2015 to 2019. Data from the Cancer Information System (Sistema de Informação do Câncer - SISCAN) were obtained from the Technology Department of the public health system (Departamento de Informática do Sistema Único de Saúde - DATASUS). Results: When comparing data from the Breast Cancer Information System (Sistema de Informação do Câncer de Mama - SISMAMA) from 2015 to 2019, we found 8,569,457 mammographies, of which 5,216,473 were performed in women aged 50 years to 69 years, which corresponds to $60.87 \%$ of the procedures. In addition, $4.90 \%$ of these women were high-risk individuals, and $1.24 \%$ had been treated for breast cancer. Mammography reports showed that $12.01 \%$ of the results were inconclusive, $38.28 \%$ were normal, $46.12 \%$ had a benign radiological finding, $2.58 \%$ had a probably benign finding, $0.78 \%$ had a suspicious finding, $0.14 \%$ had a highly suspicious finding, and $0.04 \%$ had malignant confirmation. The proportion of BI-RADS categories 4, 5, and 6 totaled 83,852 screenings, the equivalent to $0.97 \%$ of reports. In addition, $59.49 \%(49,891)$ of women who presented mammographic findings with malignant characteristics belonged to the age group 50-69 years. Conclusion: This study concluded that the strategy of biennial breast cancer screening shows scientific evidence of mortality reduction, given that $59.49 \%$ of the reports with malignant characteristics corresponded to the age group 50 to 69 years. However, the data presented did not allow calculating the number of women outside this age group who do not receive care and develop breast cancer. 